\title{
Successful resuscitation after prolonged periods of cardiac arrest: A new field in cardiac surgery
}

\author{
Georg Trummer, MD, ${ }^{\mathrm{a}}$ Katharina Foerster, MD, ${ }^{\mathrm{a}}$ Gerald D. Buckberg, MD, ${ }^{\mathrm{b}}$ Christoph Benk, MD, ${ }^{\mathrm{a}}$ \\ Claudia Heilmann, MD, ${ }^{\mathrm{a}}$ Irina Mader, MD, ${ }^{\mathrm{a}}$ Friedrich Feuerhake, MD, ${ }^{\mathrm{a}}$ Oliver Liakopoulos, MD, ${ }^{\mathrm{b}}$ \\ Kerstin Brehm, MD, ${ }^{\mathrm{a}}$ and Friedhelm Beyersdorf, $\mathrm{MD}^{\mathrm{a}}$
}

Objective: Cardiopulmonary resuscitation is associated with high mortality and poor neurological recovery. Cardiopulmonary resuscitation can cause ischemia-reperfusion injury of the whole body and brain. We assessed the hypothesis that controlled reperfusion of the whole body with cardiopulmonary bypass would limit reperfusion injury after 15 minutes of normothermic cardiac arrest with better survival and neurological recovery.

Methods: Eleven pigs were exposed to normothermic ischemia for 15 minutes by inducing ventricular fibrillation, followed by cardiopulmonary resuscitation (control group, $n=4$ ) or 60 minutes of cardiopulmonary bypass (treatment group, $\mathrm{n}=7$ ). Conditions of reperfusion and the reperfusate were controlled with cardiopulmonary bypass. Animals were observed for up to 7 days, and neurological assessment (Neurological Deficit Score: 0, normal; 500, brain death), magnetic resonance imaging, and brain histology were performed.

Results: All animals in the control group died after 20 minutes of cardiopulmonary resuscitation $(n=4)$. All $(\mathrm{n}=7)$ survived in the treatment group. Clinically apparent neurological recovery occurred within 24 hours; 1 fully conscious pig could not walk. The Neurological Deficit Score was $98 \pm 31$ in all animals $(\mathrm{n}=7)$ after 24 hours and decreased to 0 after 48 hours in 4 of 5 eligible animals; 1 animal had a Neurological Deficit Score of 110 after 3 days. Brain histology revealed hypoxic and apoptotic neurons with an inconclusive correlation regarding neurological recovery.

Conclusion: Clinically apparent neurological recovery after a period of 15 minutes of cardiac arrest occurred with cardiopulmonary bypass instead of cardiopulmonary resuscitation for reperfusing the whole body. This approach contrasts with cardiopulmonary resuscitation, in which resuscitation has been reported as successful after only 3 to 5 minutes of cardiac arrest. Cardiopulmonary bypass might be a key to improve survival and neurological recovery after cardiac arrest. (J Thorac Cardiovasc Surg 2010;139:1325-32)

Supplemental material is available online.

Sudden cardiac arrest (CA) is the leading worldwide cause of death. ${ }^{1}$ Cardiopulmonary resuscitation (CPR) with standard techniques after CA restores normal cerebral and myocardial function only, provided it occurs within the first 3 to 5 minutes after circulatory standstill. ${ }^{2}$ Attempts to start CPR after 10 minutes of $\mathrm{CA}$ will result in mortality rates of greater than $70 \%{ }^{3}$ Although successful resuscitation is possible in

\footnotetext{
From the School of Medicine, ${ }^{\mathrm{a}}$ Albert-Ludwigs-University Freiburg, Freiburg, Germany; and the David Geffen School of Medicine, ${ }^{\mathrm{b}}$ University of California, Los Angeles, Calif.

Disclosures: None.

Read at the Eighty-ninth Annual Meeting of The American Association for Thoracic Surgery, Boston, Mass, May 9-13, 2009.

Received for publication April 14, 2009; revisions received July 23, 2009; accepted for publication Aug 9, 2009.

Address for reprints: Friedhelm Beyersdorf, MD, Department of Cardiovascular Surgery, Albert-Ludwigs-University Freiburg, Hugstetter Str. 55, 79106 Freiburg, Germany (E-mail: friedhelm.beyersdorf@uniklink-freiburg.de). $0022-5223 / \$ 36.00$

Copyright $(c) 2010$ by The American Association for Thoracic Surgery doi:10.1016/j.jtcvs.2009.08.046
}

$20 \%$ to $40 \%$ of patients, hospital discharge after initially successful resuscitation is only approximately $10 \%{ }^{4-6} \mathrm{An}$ other $25 \%$ to $40 \%$ of patients experience an unwitnessed arrest with longer periods of CA; only approximately $1 \%$ to $2 \%$ of them can be discharged from the hospital. ${ }^{5}$

Time is the critical factor in determining the outcomes of patients after CPR as long as normal blood is restored under normal conditions. However, our studies demonstrated that tissue can be salvaged for much longer periods of time if the initial reperfusion after a significant ischemic insult is controlled (ie, the condition of reperfusion and the composition of the reperfusate).$^{7-9}$ The beneficial effects of this treatment regimen are apparent in cardiac and skeletal muscle, liver, lung, and renal tissue., ${ }^{7,8,10-13}$ In this report we show data of clinically apparent neurological, myocardial, and renal recovery after 15 minutes of CA. This might present the opportunity for a new definition of death, expanding the time window for successful resuscitation.

\section{MATERIAL AND METHODS}

Pigs (Deutsche Landrasse) received care in compliance with the rules and regulations for the use of laboratory animals of the Regierungspräsidium Freiburg, Germany. Protocol 1 (Registration code G-05/64) allowed experiments with a follow-up time of 24 hours, and protocol 2 (Registration code G-07/04) allowed observation for up to 7 days. 


$\begin{array}{|ll|}\text { Abbreviations and Acronyms } \\ \text { ADC } & =\text { apparent diffusion coefficient } \\ \text { ALT } & =\text { alanine aminotransferase } \\ \text { AST } & =\text { aspartate aminotransferase } \\ \text { BW } & =\text { body weight } \\ \text { CA } & =\text { cardiac arrest } \\ \text { CPB } & =\text { cardiopulmonary bypass } \\ \text { CPR } & =\text { cardiopulmonary resuscitation } \\ \text { CPR-ALS } & =\text { conventional cardiopulmonary } \\ & \text { resuscitation with advanced life } \\ \text { MAP } & \text { support } \\ \text { MRI } & =\text { mean arterial pressure } \\ \text { NDS } & =\text { magnetic resonance imaging } \\ \text { VF } & =\text { ventricular fibrillation } \\ & \end{array}$

\section{Experimental Groups}

The control group $(n=4)$ underwent circulatory arrest caused by $15 \mathrm{~min}$ utes of ventricular fibrillation (VF), followed by conventional CPR with advanced life support (CPR-ALS). In the treatment group $(n=7)$ circulatory arrest was caused by 15 minutes of VF, followed by reperfusion of the whole body with cardiopulmonary bypass (CPB).

\section{Control Group}

Animals (55.3 $\pm 5.7 \mathrm{~kg}$ body weight [BW]) were premedicated with 0.5 $\mathrm{mg} / \mathrm{kg}$ BW midazolam and $20 \mathrm{mg} / \mathrm{kg}$ BW ketamine intramuscularly and anesthetized with propofol $(1 \%)$. Endotracheal intubation followed intravenous pancuronium $(0.2 \mathrm{mg} / \mathrm{kg} \mathrm{BW})$, and 12 to 15 breaths/min were provided by a volume-controlled ventilator (Servo 900C; Siemens Elema, Solna, Sweden) at 10 to $15 \mathrm{~mL} / \mathrm{kg} \mathrm{BW}$ tidal volume and $5 \mathrm{~mm} \mathrm{Hg}$ positive end-expiratory pressure, with setting adjustment to normalize oxygen and carbon dioxide tension and $\mathrm{pH}$ values. Anesthesia and muscle paralysis was maintained with fentanyl $\left(2 \mu \mathrm{g} \cdot \mathrm{kg}^{-1} \mathrm{BW} \cdot \mathrm{h}^{-1}\right)$, isoflurane $(1.5 \%$ to $2.0 \%)$ and pancuronium $\left(0.2 \mathrm{mg} \cdot \mathrm{kg}^{-1} \mathrm{BW} \cdot \mathrm{h}^{-1}\right)$. Fluid requirements were substituted with Ringer solution $\left(10 \mathrm{mg} \cdot \mathrm{kg}^{-1} \mathrm{BW} \cdot \mathrm{h}^{-1}\right)$. Electrocardiographic results, body temperature, and oxygen saturation were monitored continuously.

All procedures were performed in a sterile setting; $30 \mathrm{mg} / \mathrm{kg} \mathrm{BW}$ cefotiam was administered for infection prophylaxis. Two incisions were made for vascular access (right neck) and induced VF (epigastric region).

Systemic blood pressure was monitored from the right carotid artery. A pulmonary artery catheter (Arrow International, Reading, Pa) was inserted through the right subclavian vein. Cardiac output was measured with a thermodilution technique. A bipolar catheter was approached through the epigastric incision for inducing VF. Before VF induction, heparin (300 IU/ $\mathrm{kg} \mathrm{BW})$ and pancuronium $(0.2 \mathrm{mg} / \mathrm{kg} \mathrm{BW})$ were administered systemically. A muscle relaxant was administered to reduce leg movement during defibrillation.

VF was then induced, the respirator was disconnected, and normothermic CA was maintained for 15 minutes. CPR-ALS (according to American Heart Association/American College of Cardiology standards, including manual chest compression, bag ventilation through an endotracheal tube, defibrillation, and inotropic and antiarrhythmic drug application) was started for at least 20 minutes and continued until the animal regained stable hemodynamics. If circulation could not be re-established during the 20-minute CPR-ALS period, the experiment was terminated, and the dead animal's brain was removed immediately and stored in formalin solution for histologic examination.

\section{Treatment Group}

In addition to the aforementioned procedure, animals in the treatment group $(57.0 \pm 8.5 \mathrm{~kg} \mathrm{BW})$ required a third incision (right groin) for femoral artery access.

Heparin was administered systemically ( $300 \mathrm{IU} / \mathrm{kg} \mathrm{BW}$ ), a 14F cannula was placed in the right femoral artery, and a $24 \mathrm{~F}$ cannula was inserted in the right external jugular vein (all cannulas: MEDOS Medizintechnik AG, Stolberg, Germany) before the ischemic period.

CPB included conventional 3/8-inch tubing, a membrane oxygenator (Hilite 7000), a venous reservoir (MVC 4030) and a diagonal pump (Deltastream DP2; all MEDOS Medizintechnik AG) connected to a heat exchanger (Stöckert, Sorin-Group Deutschland, Munich, Germany). We inserted an LG-6 filter in the arterial line to diminish the leukocyte-mediated endothelial injury (Pall Medical, East Hills, NY) and a probe for continuous online blood gas monitoring (CDI 500; Terumo, Ann Arbor, Mich). Priming consisted of $700 \mathrm{~mL}$ of Ringer solution and 15,000 IU of heparin. We added $300 \mathrm{~mL}$ of citrate-phosphate-dextrose (to bind calcium and prevent intracellular calcium accumulation followed by intracellular edema) and $2 \mathrm{~g}$ of magnesium sulfate (to reduce intracellular calcium by inhibiting calcium entry across cellular membranes and to displace calcium from binding sites on the sarcolemmal membrane). Mannitol 20\% (2 g/kg BW; acting as a free radical scavenger and to limit intracellular edema) and $10 \mathrm{mg} / \mathrm{kg}$ BW lidocaine (to stabilize the heart rhythm) were added to the priming solution (Table 1).

$\mathrm{CPB}$ was initiated for 60 minutes after the 15 minutes of CA. Systemic blood pressure was maintained at 30 to $40 \mathrm{~mm} \mathrm{Hg}$ for the first 3 to 5 minutes to provide gentle initial reperfusion (Table 2) and increased thereafter to 50 to $60 \mathrm{~mm} \mathrm{Hg}$ with full-flow CPB $\left(70-80 \mathrm{~mL} \cdot \mathrm{kg}^{-1} \cdot \mathrm{min}^{-1}\right)$. For faster cerebral cooling and prolongation of reduced cell metabolism, a $\mathrm{pH}$ regimen on $\mathrm{CPB}$ was set for $\mathrm{pH}$-stat for the first 30 minutes and changed to alpha-stat during rewarming.

Body temperature was decreased to $30^{\circ} \mathrm{C}$ (in reference to the recommendation of the International Liaison Committee on Resuscitation) through the $\mathrm{CPB}$ arterial reflow with a maximum gradient of $10^{\circ} \mathrm{C}$ versus the venous return. Rewarming occurred after 30 minutes to a minimum of $34^{\circ} \mathrm{C}$ after 60 minutes of CPB (Table 2) with attention to the species-specific susceptibility of malignant hyperthermia.

External defibrillation was performed after starting CPB (Marquette Hellige CardioServ, Freiburg, Germany) and repeated until a regular heart rhythm was established.

Blood gases and activated clotting times were measured every 15 to 30 minutes (Blood Gas Analyzer, Roche Cobas b 121; Roche Diagnostics $\mathrm{GmbH}$, Mannheim, Germany). CPB was stopped after 60 minutes, followed by cannula removal. The vessels were repaired, all wounds were closed, and protaminhydrochlorid (200 IU/kg BW) applied. Animals were allowed to regain consciousness, extubated, and transferred to the stable for further monitoring and care.

\section{Postoperative Care}

Animals were monitored for 24 hours (protocol 1) or 7 days (protocol 2) after CPB. Euthanasia was performed with $30 \mathrm{mg} / \mathrm{kg}$ pentobarbital and subsequent potassium chloride after 24 hours or after a magnetic resonance imaging (MRI) scan of the brain on day 7 . The brain was removed immediately after death and stored in formalin solution for histologic examination.

\section{Parameters}

Neurological scoring. Neurological status was assessed before anesthesia and every 24 hours after CPB by using a species-specific behavior scale (Neurological Deficit Score [NDS]). Appendix E1 shows the 5 general neurological examination components, with a maximum score of 100 in each category: 0 is normal, and 500 indicates brain death.

Video documentation. Key sequences of the experiments performed under the amended protocol were recorded on videotape. 
TABLE 1. Priming of CPB (700mL) and composition of the controlled reperfusate

\begin{tabular}{ll}
\hline Control cardiac rhythm & Lidocaine, $10 \mathrm{mg} / \mathrm{kg} \mathrm{BW}$ \\
Deplete leukocytes & $\mathrm{LG}-6$ filter in arterial line for the first $10 \mathrm{~min}$ \\
Hypocalcemia & $\mathrm{CPD}, 300 \mathrm{~mL}\left(\mathrm{Ca}^{++} 0.2-0.5 \mathrm{mmol} / \mathrm{L}\right)$ \\
Magnesium & $\mathrm{Mg}^{++}, 2 \mathrm{~g}$ \\
Mannitol & $2 \mathrm{~g} / \mathrm{kg} \mathrm{BW}$ \\
\hline
\end{tabular}

$\overline{C P B}$, Cardiopulmonary bypass; $B W$, body weight; $L G-6$, leukocyte reduction arterial blood filter (LeukoGuard-61 Pall Medical, East Hills, NY); CPD, citrate-phosphatedextrose.

MRI. MRI examination was performed before inducing CA (baseline), at the end of the experiment after 7 days, or, if indicated, at any time before. Animals were premedicated as described above and mechanically ventilated. The imaging protocol included these sequences: (1) axial T2weighted turbo spin echocardiographic sequence with an in-plane resolution of $0.4 \times 0.4 \mathrm{~mm}^{2}, 4-\mathrm{mm}$ slice thickness, and a total number of 23 slices and (2) axial echocardiographic planar diffusion-weighted sequence at $\mathrm{b}=$ 0 and $\mathrm{b}=1000 \mathrm{~s} / \mathrm{mm}^{2}$, with an in-plane resolution of $1.3 \times 1.3 \mathrm{~mm}^{2}$ in otherwise geometric parameters identical to the $\mathrm{T} 2$-weighted series.

Contrast-to-noise ratios of the T2-weighted series and maps of the apparent diffusion coefficient (ADC) from the selected brain regions (frontal lobe, occipital lobe, basal ganglia, hippocampus, and cerebellum) of the final MRI were compared with those of baseline images.

Histologic examinations. Brain histology from healthy pigs was performed in 3 separate animals to investigate potential damage from the procurement procedure.

Formalin-fixed brain tissues from the frontal lobe, thalamus, striatum, hippocampus, posterior brain stem, and cerebellar hemispheres were embedded in paraffin. Four to 5- $\mu \mathrm{m}$-thick sections were stained with hematoxylin and eosin; neuronal apoptosis was detected with terminal deoxynucleotidyl transferase-mediated dUTP nick end labeling staining.

Hemodynamic data. Hemodynamic measurements were taken before inducing VF (baseline) and after discontinuing CPB. Cardiac output was measured by using a thermodilution technique with derived hemodynamic parameters (cardiac index, systemic vascular resistance index, and pulmonary vascular resistance index). Number of shocks, time to regain stable heart rhythm, and total $\mathrm{CPB}$ time were recorded.

Temperature measurements. For continuous temperature measurement, a probe was placed in the nasopharyngeal region and in the $\mathrm{CPB}$ circuit lines.

Biochemical data. Arterial blood was sampled at baseline and the end of CPB. Further samples were taken at the end of the experiment.

Creatinine kinase and serum transaminases. Cellular injury was determined by measuring creatinine kinase, serum aspartate aminotransferase (AST), and alanine aminotransferase (ALT) activity by using the UV-spectrophotometric method (Sigma Chemical Co, St. Louis, Mo) and expressed as units per milliliter of plasma.

Neuron-specific enolase. Neuron-specific enolase as a marker for brain injury was quantified with an Enzyme Immunometric Assay (SynX Pharma, Inc, Toronto, Ontario, Canada).

TABLE 2. Protocol of the conditions of reperfusion

\begin{tabular}{lc}
\hline Controlled reperfusion pressure & $\begin{array}{c}30-40 \mathrm{~mm} \mathrm{Hg} \text { for the first 3-5 min } \\
\text { after circulatory arrest }\end{array}$ \\
$\begin{array}{l}\text { Controlled reperfusion flow } \\
\text { Controlled blood temperature } \\
\text { Cooling to } 30^{\circ} \mathrm{C} \text { for the first } 30 \mathrm{~min}, \\
\text { warming thereafter to } 34^{\circ} \mathrm{C}\end{array}$ \\
$\begin{array}{c}\text { Controlled blood } \mathrm{pH} \\
\mathrm{pH}-\text { stat during cooling, alpha-stat } \\
\text { during rewarming }\end{array}$ \\
\hline
\end{tabular}

$B W$, Body weight.

\section{Statistical Analysis}

To statistically evaluate the region-of-interest analysis of magnetic resonance data, we used SPSS 15.0 software (SPSS, Inc, Chicago, Ill). After proved normality, a 2-sided Student's $t$ test for equal variances and a Welsh test for unequal variances were applied. A Bonferroni correction was performed, and data were expressed as means \pm standard deviations.

\section{RESULTS}

\section{Mortality}

Control group. All animals died after a period of $20 \mathrm{~min}-$ utes of CPR-ALS. VF was not terminated, nor was stable circulation re-established.

Treatment group. All animals survived and were transferred to the stable $2.6 \pm 0.3$ hours after the end of surgical intervention.

\section{Neurological Deficit Score}

Control group. No neurological recovery was recorded because of the $100 \%$ mortality described above.

Treatment group. The NDS was $98 \pm 31$ in all animals $(\mathrm{n}=7)$ at the 24-hour time point (see Figure 1). The NDS decreased further to 0 after 48 hours in 4 of 5 animals that were eligible for the 7-day observation period (according to the amendment) and remained at 0 . Temporary seizures occurred during the early postoperative period ( $<48$ hours) in 5 animals, which were treated with intravenous application of calcium and, if necessary, benzodiazepines. One animal regained full consciousness and accepted food and water but was unable to stand up and walk within 3 days after surgical intervention (NDS $=110)$. It was killed on day 3 .

\section{VF Induction and Electrocardiographic Changes During 15 Minutes of Ischemia}

VF induction was established quickly in all experiments $(n=11)$. Initial electrocardiographic results showed highfrequency VF followed by torsade de pointes, which diminished within 3 to 5 minutes to low-amplitude VF close to the zero line. No animal regained a regular rhythm spontaneously.

\section{VF Termination}

Control group. One hundred percent mortality $(n=4)$ occurred because VF could not be terminated despite recurrent defibrillation and intravenous antiarrhythmic medication.

Treatment group. External defibrillation $(9 \pm 5$ shocks) with increasing energy up to 360 Joules was necessary in all animals $(n=7)$ during the first minutes of reperfusion. A regular heart rhythm was established within $4.8 \pm 1.8$ minutes after initiating $\mathrm{CPB}$ and maintained during and after CPB (see Table E1).

\section{Hemodynamic Data}

Control group. Mean arterial pressure (MAP) was maintained at $32.7 \pm 10.6 \mathrm{~mm} \mathrm{Hg}$ during CPR-ALS. Flow was not measured in this group. 


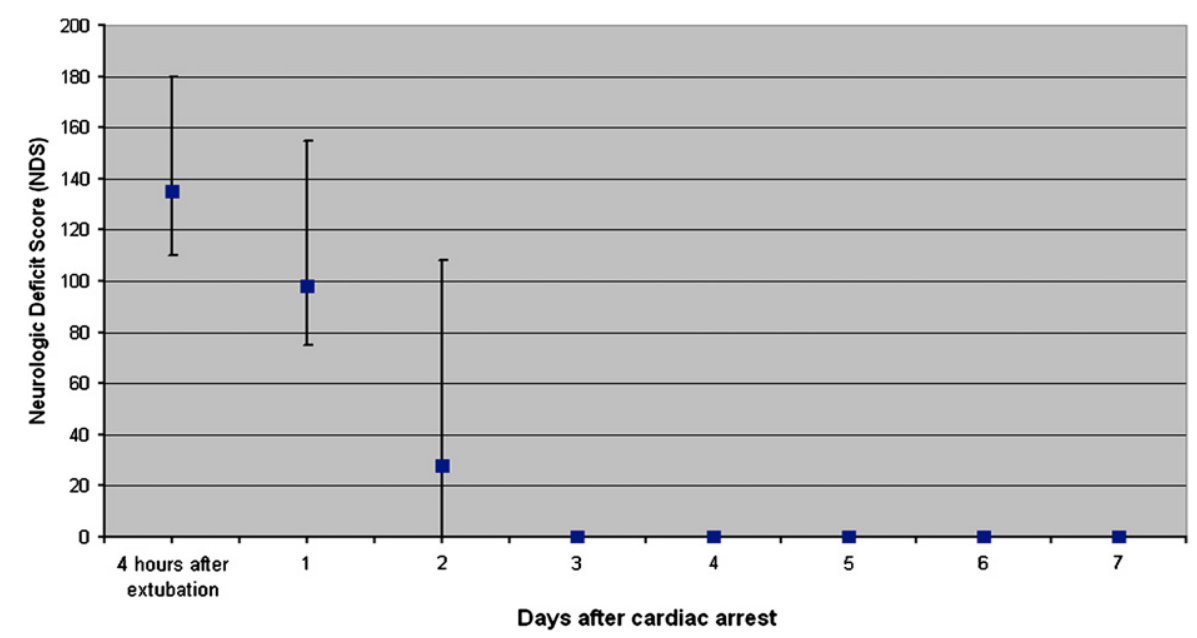

FIGURE 1. Neurological Deficit Score (NDS): treatment group. The experimental group included 7 animals. The NDS was $98 \pm 31$ after 24 hours. Two animals had to be killed after 24 hours during the limited observation time of the initial protocol. The extended observation period was applicable for 5 animals. The NDS decreased to 0 after 48 hours in 4 of these 5 animals. One animal regained full consciousness and accepted food and water but was unable to get up and walk within the first 3 days after the operation (expressed as an NDS of 110 at that time).

Treatment group. As shown in one experiment in Figure E2, MAP decreased within 30 seconds after VF induction to $15 \pm 4 \mathrm{~mm} \mathrm{Hg}$. MAP increased within the following 3 to 5 minutes to a maximum of $19 \pm 5 \mathrm{~mm} \mathrm{Hg}$, followed by a final decrease to $8 \pm 6 \mathrm{~mm} \mathrm{Hg}$. Pulmonary artery pressures decreased to values corresponding to central venous pressure.

MAP after the start of CPB was kept at $35 \pm 7 \mathrm{~mm} \mathrm{Hg}$ (2 minutes) and $46 \pm 16 \mathrm{~mm} \mathrm{Hg}$ after 5 minutes, with corresponding flow rates of a CPB of $44 \pm 10 \mathrm{~mL} \cdot \mathrm{kg}^{-1}$. $\min ^{-1}$ (2 minutes) and $46 \pm 12 \mathrm{~mL} \cdot \mathrm{kg}^{-1} \cdot \min ^{-1}(5 \mathrm{~min})$. Low-dose norepinephrine was used in all experiments to maintain an arterial pressure between 50 and $60 \mathrm{~mm} \mathrm{Hg}$ with a CPB flow of $67 \pm 13 \mathrm{~mL} \cdot \mathrm{kg}^{-1} \cdot \mathrm{min}^{-1}$.

\section{Nasopharyngeal Temperature}

Control group. The animals' temperature decreased from $37.3^{\circ} \mathrm{C} \pm 0.5^{\circ} \mathrm{C}$ to $35.9^{\circ} \mathrm{C} \pm 0.3^{\circ} \mathrm{C}$ after 15 minutes of VF. The temperature at the end of the experiment after 20 minutes of CPR-ALS was $35.1^{\circ} \mathrm{C} \pm 0.4^{\circ} \mathrm{C}$.

Treatment group. Temperature decreased from $37.1^{\circ} \mathrm{C} \pm$ $0.3^{\circ} \mathrm{C}$ to $36.1^{\circ} \mathrm{C} \pm 0.4^{\circ} \mathrm{C}$ after 15 minutes of VF. After the start of CPB, the animals were immediately cooled down. Six animals $(\mathrm{n}=6)$ attained a nasopharyngeal temperature of $29.6^{\circ} \mathrm{C} \pm 2.1^{\circ} \mathrm{C}$ after 30 minutes of CPB. Because of heat-exchanger failure, 1 animal was cooled to $25.0^{\circ} \mathrm{C}$ after 30 minutes with an uneventful consecutive course. All animals $(n=7)$ in the experimental group were rewarmed on $\mathrm{CPB}$, achieving a temperature of $35.0^{\circ} \mathrm{C} \pm 0.9^{\circ} \mathrm{C}$ at the time of separation from $\mathrm{CPB}$.

\section{pH Values}

Control group. After 15 minutes of $\mathrm{CA}$, the earliest blood draw was possible after 3 to 5 minutes of manual chest com- pression. Metabolic alkalosis $(\mathrm{pH} 7.57 \pm 0.18)$ was present at this time.

Treatment group. Drawing blood from the arterial line in the right carotid artery was not possible after 15 minutes of CA. We therefore obtained the blood gases from the arterial line of the CPB 1 to 2 minutes after the start of CPB. Starting from normal values at baseline $(\mathrm{pH} 7.48 \pm 0.40)$, blood gas analysis indicated a metabolic acidosis $(\mathrm{pH} 7.19$ \pm 0.10 ) in all animals after 15 minutes of VF. $\mathrm{pH}$ values remained low by using the $\mathrm{pH}$-stat strategy during the first 30 minutes of $\mathrm{CPB}$ and returned to $\mathrm{pH} 7.36 \pm 0.05$ with the alpha-stat strategy during rewarming on $\mathrm{CPB}$.

\section{Separation From CPB and Respirator Weaning}

Control group. No control pigs developed circulation, and all animals died after a period of 20 minutes of CPR-ALS. Treatment group. All animals were weaned off CPB after $64 \pm 5$ minutes (see Table E1). In 4 animals low-dosage inotropic support $\left(0.06 \mu \mathrm{g} \cdot \mathrm{kg}^{-1} \mathrm{BW} \cdot \mathrm{min}^{-1}\right.$ epinephrine or 10 $\mu \mathrm{g} \cdot \mathrm{kg}^{-1} \mathrm{BW} \cdot \min ^{-1}$ dopamine) was necessary at the time of weaning from CPB. The other animals $(n=4)$ were separated from CPB without inotropic support. No animal required inotropic or vasoactive agents 2 hours after CPB. The animals were weaned from the respirator $140.0 \pm 8.7$ minutes after $\mathrm{CPB}$. Heart rate and cardiac index were increasing more at the end of the operation than at baseline without increased filling pressures (see Table E2).

\section{Renal Function}

Diuresis was sufficient in all 7 animals in the treatment group. Blood gas analysis at the end of the experiment revealed baseline values for hematocrit, potassium, and $\mathrm{pH}$. 


\section{MRI}

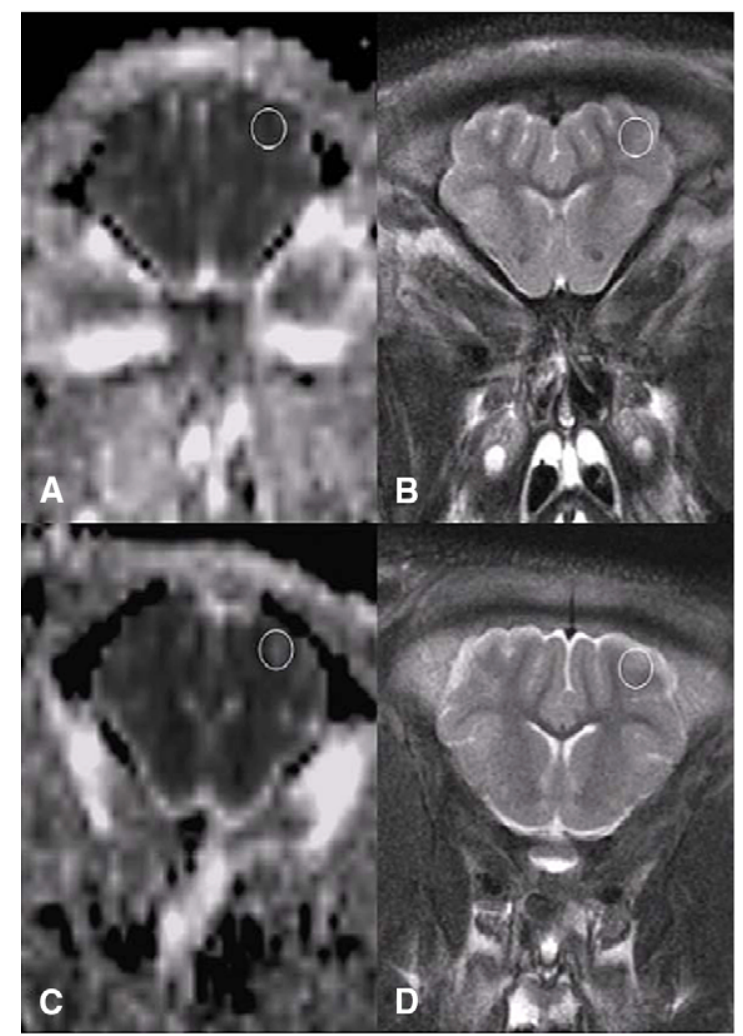

A

\section{Brain histology}
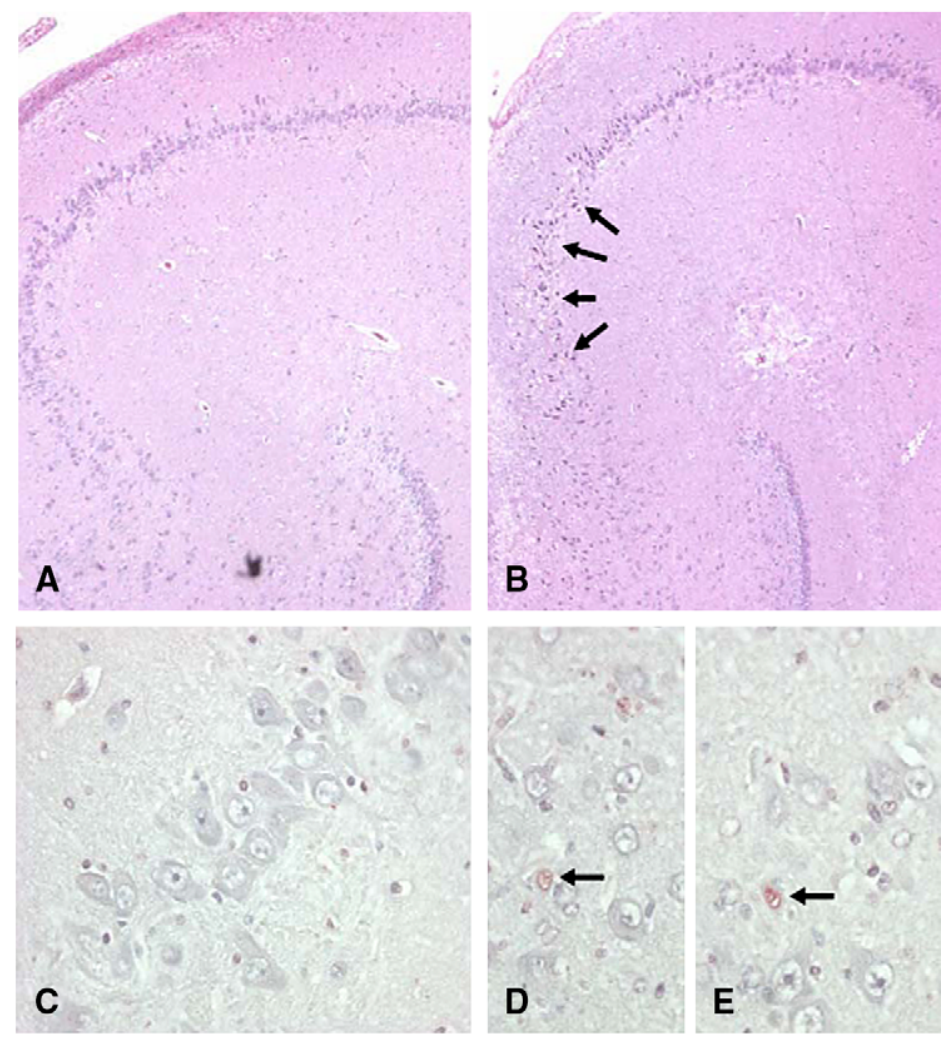

B

FIGURE 2. Magnetic resonance imaging (MRI) and brain histology. A, MRI was performed with a focus on apparent diffusion coefficient (ADC) and T2weighted (T2W) brain images. White circles are placed within the region of interest. Coronary slices of the frontal lobe (panel A, ADC; panel B, T2 weighted) represent the animals' status 7 days after normothermic ischemia. Note that ADC is lower 7 days after normothermic ischemia as a substrate of intracellular edema after acute ischemia of the brain (panel C, ADC), whereas T2-weighted slices do not show a change in signal intensity compared to control (panel D, T2). B, Histology of the brain of a healthy animal without ischemia (left: panels $A$ and $C$ ) compared with that of an animal after 15 minutes of cardiac arrest with complete functional recovery (right: panels $B, D$, and $E$ ). Hematoxylin and eosin stains showing hypoxic neurons, astrocytosis, and blood vessel and macrophage activation (panel B, arrows), which are absent in the control animal. Neuronal apoptosis is absent in the control animal (panel $C$ ) and confirmed in the hypoxic animals (panels $D$ and $E$, terminal deoxynucleotidyl transferase-mediated dUTP nick end labeling staining).

\section{Biochemical Data}

Control group. Biochemical data showed values close to baseline at the end of the experiment after 20 minutes of CPR-ALS (see Table E3).

Treatment group. Animals (see Table E4) showed slightly increased AST $(49 \pm 33 \mathrm{U} / \mathrm{L})$ and ALT $(93 \pm 77 \mathrm{U} / \mathrm{L})$ values at the end of the experiment compared with baseline values (AST, $34 \pm 8 \mathrm{U} / \mathrm{L}$; ALT, $37 \pm 17 \mathrm{U} / \mathrm{L}$ ). After intramuscular injection, creatinine kinase levels were increased at baseline $(2171 \pm 859 \mathrm{U} / \mathrm{L})$, increasing after CPB (3225 $\pm 2587 \mathrm{U} / \mathrm{L})$ and decreasing at the end of the experiment $(2739 \pm 2272 \mathrm{U} / \mathrm{L})$. Neuron-specific enolase levels remained at baseline values $(0.20 \pm 0.10 \mu \mathrm{g} / \mathrm{L})$ at the end of CPB $(0.20 \pm 0.08 \mu \mathrm{g} / \mathrm{L})$, with higher values at the end of the experiment after 7 days $(1.00 \pm 0.30 \mu \mathrm{g} / \mathrm{L})$.
Blood gas analysis showed a rapid decrease in ionized calcium levels from $1.39 \pm 0.03 \mathrm{mmol} / \mathrm{L}$ (baseline) to $0.58 \pm$ $0.28 \mathrm{mmol} / \mathrm{L}$ at the 10 -minute time point after the start of $\mathrm{CPB}$ but returned to $1.14 \pm 0.13 \mathrm{mmol} / \mathrm{L}$ at the end of surgical intervention.

\section{MRI}

In the treatment group MRI examination was performed at baseline $(\mathrm{n}=5)$ and at the end of the experiment on day 7 $(n=4)$. The MRI of one animal took place after 72 hours.

The ADC of the frontal gray matter differed significantly from that at baseline $(52.3 \pm 17.1$ vs $17.6 \pm 17.0, P=.01)$. No significant differences were apparent in any of the other region of interest measurements from the ADC maps and T2-weighted images. An ADC map and T2-weighted 
images of the brain before and after treatment are presented (Figure 2, A).

\section{Brain Histology}

In the treatment group generalized hypoxic damage was moderate. Individual hypoxic neurons and diffusely spread neurons underwent apoptosis. Morphologic signs of hypoxic brain damage were mainly confined to the hypoxia-sensitive CA4, CA3, and CA1 hippocampal areas, whereas $\mathrm{CA} 2$ and the other brain regions revealed minor changes (Figure 2, B).

\section{DISCUSSION}

Despite continuous efforts in the medical community, the chances for survival after sudden CA remain poor, and if survived, it is often accompanied by persistent cerebral failure. $^{1,14}$ Myocardial stunning and brain reperfusion injury follow when spontaneous circulation is restored through CPR. ${ }^{2,15}$ The duration of CA before CPR is the most important outcome determinant; survival is up to $50 \%$ after early defibrillation and CPR within 4 to 5 minutes, but when that interval is doubled, survival is negligible. ${ }^{2}$ It is generally believed that irreversible brain injury occurs after 5 minutes of no-flow, normothermic whole-body ischemia (CA), and neurological injury increases proportionally to longer CA duration. ${ }^{16}$ Consequently, delaying CPR after prolonged CA periods ( $>10-15$ minutes) results in greater than $95 \%$ mortality and usually irreversible brain damage in survivors. ${ }^{5}$

Slightly better overall outcomes follow when emergency $\mathrm{CPB}$ is initiated to restore cardiocerebral resuscitation after effective CPR-ALS to treat CA, but neurological mortality remains high. ${ }^{17}$ Eighty percent to $100 \%$ survival is experimentally possible when normothermic CPB is introduced 5 to 10 minutes after $\mathrm{CA}$ in dogs, ${ }^{16}$ but mortality increases to approximately $80 \%$, and no neurological recovery is possible when CPR-ALS is started after 12.5 minutes of experimental CA. ${ }^{18}$ Yet using CPB for mechanical circulatory support after 12.5 minutes of $\mathrm{CA}$ increased survival to $70 \%$, and $50 \%$ of those dogs regained consciousness after 72 hours. ${ }^{19}$ However, when extending the CA duration to 15 minutes, there is no survival with CPR-ALS, and although CPB increases survival to approximately $25 \%$ to $80 \%$, it does not compensate for severely impaired neurological recovery. ${ }^{16}$

In sharp contrast to those studies, we did not use CPR and succeeded in demonstrating clinically apparent neurological and myocardial recovery after 15 minutes of normothermic CA in pigs treated by controlling the conditions and composition of the reperfusate. This study design differs from prior body ischemic insult (CA) studies in which CPR-ALS or $\mathrm{CPB}$ resuscitation protocols used normal blood as the primary reperfusate. The tenet of our approach is that immediate normal blood cerebral reperfusion is responsible for the fate of cerebral tissue because neurons are known to function for up to
60 minutes during ischemia alone, ${ }^{20}$ an implication consistent with prior statements that the maximum ischemic tolerance of myocardial and skeletal muscle cells is unknown. 9,21

Lethal ischemia-reperfusion injury can occur in already injured cerebral tissue and cardiac muscle cells when normal blood is the primary reperfusate because the latter can activate potential mediators that include oxygen and calcium paradox, $\mathrm{pH}$ paradox, inflammation, calcium overload, and water accumulation within the cell. ${ }^{9,22}$ Cerebral dysfunction can be exacerbated secondarily by cerebral perfusion reperfusion injury that triggers delayed neuronal cell death during the first 3 reflow days. ${ }^{15}$

Deep hypothermic circulatory arrest is an important tool for neuroprotection during aortic surgery and allows a safe period of circulatory arrest of 25 minutes at $18^{\circ} \mathrm{C}$. The implementation of strategies to control the conditions of reperfusion and the reperfusate after deep hypothermic circulatory arrest allows prolonged periods of CA up to 90 minutes with clinically apparent neurological recovery. ${ }^{23}$ Therefore our new concept is designed to counteract the mediators of reperfusion injury by controlling the conditions of reperfusion and the composition of the initial reperfusion phase (Tables 1 and 2) during an initially controlled reperfusion phase as primary treatment before normal blood from the whole body enters the ischemically injured cells. This global approach is based on our previous studies of ischemia-reperfusion injury and their treatment in isolated organs, such as the myocardium, ${ }^{8,9,22}$ skeletal muscle, ${ }^{13}$ lung, ${ }^{11}$ and kidney, ${ }^{12}$ as well as in the whole body during hypothermic CA. ${ }^{24}$ Unlike this concept, conventional CPRALS involves uncontrolled reperfusion of the whole body with only normal blood perfusion and a cerebral perfusion pressure seldom exceeding $40 \mathrm{~mm} \mathrm{Hg}$, providing only $10 \%$ to $15 \%$ of normal cerebral blood flow, an intervention that might do more damage than no flow at all.

Our data show survival of all $(\mathrm{n}=7)$ animals in the treatment group, with clinically apparent neurological recovery in 6 of 7. Follow-up was possible in 5 animals for 7 days, and neurological recovery persisted during that period. Myocardial recovery occurred quickly: few defibrillations were required on $\mathrm{CPB}$ to terminate VF and establish stable cardiac rhythm, followed by a short time on CBP. Early extubation and unimpaired hemodynamic data highlight the treatment group's impressive cardiac performance, which stands in sharp contrast to that of the control group, in which all animals undergoing CPR-ALS died from continuous VF or the inability to establish stable circulation.

Despite clinically apparent neurological recovery, MRI examination of the brain revealed intracellular edema in the frontal gray matter after 7 days. We observed no significant differences in any of the other ADC maps and T2weighted images. Brain histology after 7 days revealed that most brain regions had mild histologic changes, mainly in the hypoxia-sensitive hippocampal areas CA4, CA3, and 
CA1, which showed signs of apoptosis. We conclude that a certain amount of brain damage still occurs, although to a limited extent, permitting recovery and survival. We plan to investigate this issue, which was not examined in this study, in our future research.

Study limitations include the use of juvenile animals and their potentially better neurological recovery. Beyond that, systemic heparinization for CPB was applied before CA induction, but our dosages were much lower $(300 \mathrm{IU} / \mathrm{kg}$ ) than the large dose $(700 \mathrm{IU} / \mathrm{kg})^{25}$ that improved survival and neurological recovery whereby only 2 dogs were normal and 4 of 6 were arousable. Furthermore, volatile anesthetics can limit ischemic cerebral injury. ${ }^{26}$ Our model would be more readily comparable with routine patients with $\mathrm{CA}$ if the same experiments were conducted in lightly sedated animals without administering heparin, muscle relaxants, isoflurane, and mechanical ventilation. However, we did not get approval from the regulatory authorities for animal research to use lightly sedated animals.

In conclusion, we present data showing $100 \%$ survival of pigs after 15 minutes of normothermic CA and clinically apparent neurological recovery in 6 of 7. This is in contrast to current treatment methods, with which resuscitation is only successful after CA times of 3 to 5 minutes, followed by frequent neurological damage in the few survivors. This far better survival and neurological outcome after prolonged cardiac standstill is possible by treating the tissues damaged previously by ischemia (CA) before normal blood reperfusion is reinstituted. This new treatment consists of a modified reperfusate and controlled conditions of reperfusion for the initial 60 minutes using peripheral extracorporeal circulation. We thus provide evidence that challenges the usual $100 \%$ mortality after 15 minutes of normothermic CA. If our experimental results are confirmed by others in future studies, resuscitation with $\mathrm{CPB}$ might evolve as a powerful new tool in patients with sudden CA.

\section{References}

1. Priori SG, Aliot E, Blomstrom-Lundqvist C, Bossaert L, Breithardt G, Brugada P, et al. Task Force on Sudden Cardiac Death of the European Society of Cardiology. Eur Heart J. 2001;22:1374-450.

2. Weisfeldt ML, Becker LB. Resuscitation after cardiac arrest: a 3-phase time-sensitive model. JAMA. 2002;288:3035-8.

3. Schultz SC, Cullinane DC, Pasquale MD, Magnant C, Evans SR. Predicting inhospital mortality during cardiopulmonary resuscitation. Resuscitation. 1996; 33:13-7.

4. Rea TD, Pearce RM, Raghunathan TE, Lemaitre RN, Sotoodehnia N, Jouven X, et al. Incidence of out-of-hospital cardiac arrest. Am J Cardiol. 2004;93: 1455-60.

5. Fredriksson M, Herlitz J, Engdahl J. Nineteen years' experience of out-of-hospital cardiac arrest in Gothenburg-reported in Utstein style. Resuscitation. 2003;58: $37-47$.

6. El Menyar AA. The resuscitation outcome: revisit the story of the stony heart. Chest. 2005;128:2835-46.

7. Allen BS, Okamoto F, Buckberg GD, Bugyi H, Young H, Leaf J, et al. Immediate functional recovery after six hours of regional ischemia by careful control of conditions of reperfusion and composition of reperfusate. J Thorac Cardiovasc Surg. 1986;92:621-35.
8. Beyersdorf F, Kirsh M, Buckberg GD, Allen BS. Warm glutamate/aspartateenriched blood cardioplegic solution for perioperative sudden death. $J$ Thorac Cardiovasc Surg. 1992;104:1141-7.

9. Buckberg GD. When is cardiac muscle damaged irreversibly? J Thorac Cardiovasc Surg. 1986;92:483-7.

10. Buckberg GD. Strategies and logic of cardioplegic delivery to prevent, avoid, and reverse ischemic and reperfusion damage. J Thorac Cardiovasc Surg. 1987;93: 127-39.

11. Halldorsson AO, Kronon M, Allen BS, Rahman S, Wang T, Layland M, et al Controlled reperfusion prevents pulmonary injury after 24 hours of lung preservation. Ann Thorac Surg. 1998;66:877-84.

12. Haab F, Julia P, Nochy D, Cambillau M, Fabiani JN, Thibault P. Improvement of postischemic renal function by limitation of initial reperfusion pressure. J Urol. 1996;155:1089-93

13. Beyersdorf F, Schlensak C. Controlled reperfusion after acute and persistent limb ischemia. Semin Vasc Surg. 2009;22:52-7.

14. Rogove HJ, Safar P, Sutton-Tyrrell K, Abramson NS. Old age does not negate good cerebral outcome after cardiopulmonary resuscitation: analyses from the brain resuscitation clinical trials. The Brain Resuscitation Clinical Trial I and II Study Groups. Crit Care Med. 1995;23:18-25.

15. Madl C, Holzer M. Brain function after resuscitation from cardiac arrest. Curr Opin Crit Care. 2004;10:213-7

16. Safar P, Abramson NS, Angelos M, Cantadore R, Leonov Y, Levine R, et al. Emergency cardiopulmonary bypass for resuscitation from prolonged cardiac arrest. Am J Emerg Med. 1990;8:55-67.

17. Sung K, Lee YT, Park PW, Park KH, Jun TG, Yang JH, et al. Improved surviva after cardiac arrest using emergent autopriming percutaneous cardiopulmonary support. Ann Thorac Surg. 2006;82:651-6.

18. Levine R, Gorayeb M, Safar P, Abramson N, Stezoski W, Kelsey S. Cardiopulmonary bypass after cardiac arrest and prolonged closed-chest CPR in dogs. Ann Emerg Med. 1987;16:620-7.

19. Pretto E, Safar P, Saito R, Stezoski W, Kelsey S. Cardiopulmonary bypass after prolonged cardiac arrest in dogs. Ann Emerg Med. 1987;16:611-9.

20. Boldyrev A, Song R, Dyatlov VA, Lawrence DA, Carpenter DO. Neuronal cell death and reactive oxygen species. Cell Mol Neurobiol. 2000;20:433-50.

21. Beyersdorf F, Unger A, Wildhirt A, Kretzer U, Deutschlander N, Krueger S, et al Studies of reperfusion injury in skeletal muscle: preserved cellular viability after extended periods of warm ischemia. J Cardiovasc Surg (Torino). 1991;32:664-76.

22. Yellon DM, Hausenloy DJ. Myocardial reperfusion injury. N Engl J Med. 2007; 357:1121-35.

23. Allen BS, Veluz JS, Buckberg GD, Aeberhard E, Ignarro LJ. Deep hypothermic circulatory arrest and global reperfusion injury: avoidance by making a pump prime reperfusate-a new concept. J Thorac Cardiovasc Surg. 2003;125:625-32.

24. Allen BS, Castella M, Buckberg GD, Tan Z. Conditioned blood reperfusion markedly enhances neurologic recovery after prolonged cerebral ischemia. $J$ Thorac Cardiovasc Surg. 2003;126:1851-8.

25. Ichinose $\mathrm{K}$, Okamoto $\mathrm{T}$, Tanimoto $\mathrm{H}$, Taguchi $\mathrm{H}$, Tashiro $\mathrm{M}$, Sugita $\mathrm{M}$, et al. A moderate dose of propofol and rapidly induced mild hypothermia with extracorporeal lung and heart assist (ECLHA) improve the neurological outcome after prolonged cardiac arrest in dogs. Resuscitation. 2006;70:275-84.

26. Kawaguchi M, Furuya H, Patel PM. Neuroprotective effects of anesthetic agents. J Anesth. 2005;19:150-6.

\section{Discussion}

Dr Ani Anyanwu (New York, NY). I have nothing to disclose.

This study is unique, and its authors are to be commended because they demonstrated survival with relatively preserved neurological recovery after 15 minutes of normothermic CA. Your study differs from prior studies of resuscitative CPB by applying controlled reperfusion, the theory being that subjecting the ischemic body cells to normotensive normal blood reperfusion as in conventional CPB might be deleterious and result in secondary injury.

There are, however, several components to your intervention that could explain the results.

This leads to the first of my 3 questions. You necessarily heparinized your animals before $\mathrm{CA}$, presumably to allow cannulation of vessels in preparation for later perfusion. To what degree do 
you think heparinization could have contributed to your results? Did you consider an alternative study design in which the animals were heparinized and swiftly cannulated after CA?

Dr Trummer. Thank you very much for those very good questions.

We expected this problem in our study, and we heparinized only $300 \mathrm{U} / \mathrm{kg} \mathrm{BW}$. The control group was heparinized at the same time, and the animals in the control group died. Therefore we do not really see a big effect on the heparin.

On the other hand, with the knowledge we have from those experiments right now, we also would assume it is possible to place the catheters without administering heparin, but then you might have the risk of losing more animals in the treatment group because of clotting. However, it should be possible just to start the pump only with heparin and not administer heparin before.

Dr Anyanwu. Obviously in a clinical situation you could not heparinize before arrest.

This takes me to the issue of the control group, which you mentioned. Your control group consisted of animals undergoing conventional CPR after prolonged normothermic arrest, a condition that we know from previous studies is not survivable. This was expectedly demonstrated in your results. I would argue therefore that your control group was wasted and somewhat irrelevant. The preferred control group would have been animals undergoing conventional hypothermic CPB after prolonged arrest. In that way we could separate the effect of the controlled reperfusion from that of CPB. This leads to my second question: What was the basis for your choice of control group for this experiment?

Dr Trummer. Thank you very much for this comment. We performed many pilot studies before this study. In those pilot studies we performed CPR after 15 minutes of arrest and then started the animals on bypass. Primarily in this group, $35 \%$ of the animals died, and the subsequent $65 \%$, or two thirds of them, had to undergo bypass because they deteriorated with circulation.

We thought that would not be the right group to compare because we hypothesized that conventional CPR reflects an uncontrolled reperfusion. Therefore, we chose animals with conventional CPR as control group.

Dr Anyanwu. It then becomes difficult to isolate the effects of controlled reperfusion.

Finally, being a clinician, I am interested in how I can extrapolate these findings to my clinical practice. It is impractical to expect that we can use CPB to resuscitate all patients undergoing cardiopulmonary arrest. Nevertheless, assuming you repeated these experiments with conventional bypass controls and showed the same results, there would be 2 things that I would choose to take back to my practice from your study. First, when patients have CA intraoperatively or in the intensive care unit requiring emergency $\mathrm{CPB}$, then perfusion, once established, should first use a specified reperfusate and be maintained at a low pressure for the first few minutes. Second is that when I subject the heart or brain to ischemia, as in cardioplegic arrest, heart transplantation, or cerebral circulatory arrest, I should always use some form of controlled reperfusion to re-establish perfusion. Do you think these are valid extrapolations? Have you changed your own practice in any way as a result of your study?

Dr Trummer. Thank you very much for this comment. That is a thing of the future, and that is completely correct. Before we can go out to the field, we have to do it within the hospital, within the operating room or the intensive care unit; that is where we have to start it if we want to establish this new method of reperfusion. We cannot go out and eradicate CPR in the field; that is not possible right now, but it is one of the visions we have.

Dr Anyanwu. I am asking the following: if I have a patient in the operating room who has a CA, should I use a similar technique to resuscitate them today?

Dr Trummer. From the results we have right now, it should be possible to do it. We just did it now in animals but have not done it in patients yet. Once we have more results, then we would go to the ethical committee to prove that within clinical practice.

Dr Richard J. Shemin (Los Angeles, Calif). I have no disclosures.

This was a very interesting study, but the details of CPB are key to understanding exactly what is going on here. Obviously, these pigs look big, but I am sure they are juvenile pigs, and therefore the first question is this: Do you think that there is some aspect between the maturity of the animal and the potential recovery with this technique?

Dr Trummer. Thank you very much for this comment. That is a potential limitation we discussed because these are juvenile pigs, and those are around 50 to $60 \mathrm{~kg}$. However, that is a moveable size because the pigs have to stand up later on; if they are too big, they cannot stand up anymore. That is one thing how to conduct the experiment.

On the other hand, we needed a lot of things in the pump to get to this point, a low perfusion pressure and low flow. We implemented leukocyte filters; we were running them on $\mathrm{pH}$ stat, cooling them down. Therefore there were a lot of things that I was unable to present right now because we would go over the time.

Dr Shemin. So low pressure and low flow?

Dr Trummer. Low pressure, low flow, leukocyte filters in there, cooling down and leaving the animals in $\mathrm{pH}$ stat immediately to leave the cell in an acidotic environment to stop the metabolism in there. That was the goal we wanted to achieve.

Dr Shemin. So what temperatures did you cool to?

Dr Trummer. We cooled them down immediately to $30^{\circ} \mathrm{C}$, which we reached about 10 minutes after we started the pump.

Dr Shemin. One of the key aspects in your control group is that all the animals failed to achieve hemodynamic stability and died, and therefore you do not know anything about neurological recovery in that group.

Dr Trummer. However, as I mentioned before, we did some experiments at the University of California, Los Angeles, in which we saw that the animals really came out poorly after conventional CPR, irrespective of whether we started them later on bypass. If the animals do not get out of VF, mortality is $100 \%$.

Dr Shemin. The other aspect, and my final question, regards the effect of the anesthetic. Obviously both groups received it, but obviously to induce fibrillation during anesthesia actually probably has some protective effect also.

Dr Trummer. That is completely correct. And we also tried to get to this point, but right now it is not possible to conduct this experiment on an awake animal. We took electroencephalograms from the animals in previous studies and tried to keep the animal as awake as possible looking to the electroencephalograms. Therefore we save on anesthesia to avoid the protective effects, but that is the only thing we can do right now.

Dr Shemin. What anesthetic agent did you use?

Dr Trummer. Isoflurane, low dose, and propofol. 


\section{Appendix E1. Neurological Deficit Score}

A. Central nerve function (0-100 points): pupil size (0-10); eye position (0-10); light, lid, and corneal reflex (each $0-10$ ); ciliospinal and oculocephalic reflex (each $0-10$ ); auditory and gag reflex (each $0-10$ ); carinal reflex $(0-10)$

B. Respiration (0-100 points): normal (0), hyperventilation (25), abnormal (50), absent (100)

C. Motor sensory function (0-100 points): stretch reflex (0-25), motor response to pain (0-25), positioning $(0-25)$, muscle tonus $(0-25)$
E. Level of consciousness (0-100 points): normal (0), cloudy (30), delirium (45), stupor (60), coma (100)

F. Behavior (0-100 points): drinking, chewing, sitting, and standing (each 0-15); walking (0-40)

The total score is the sum of all sections $(0$, normal; 500 , brain death). Numbers in parentheses indicate scores for each parameter.

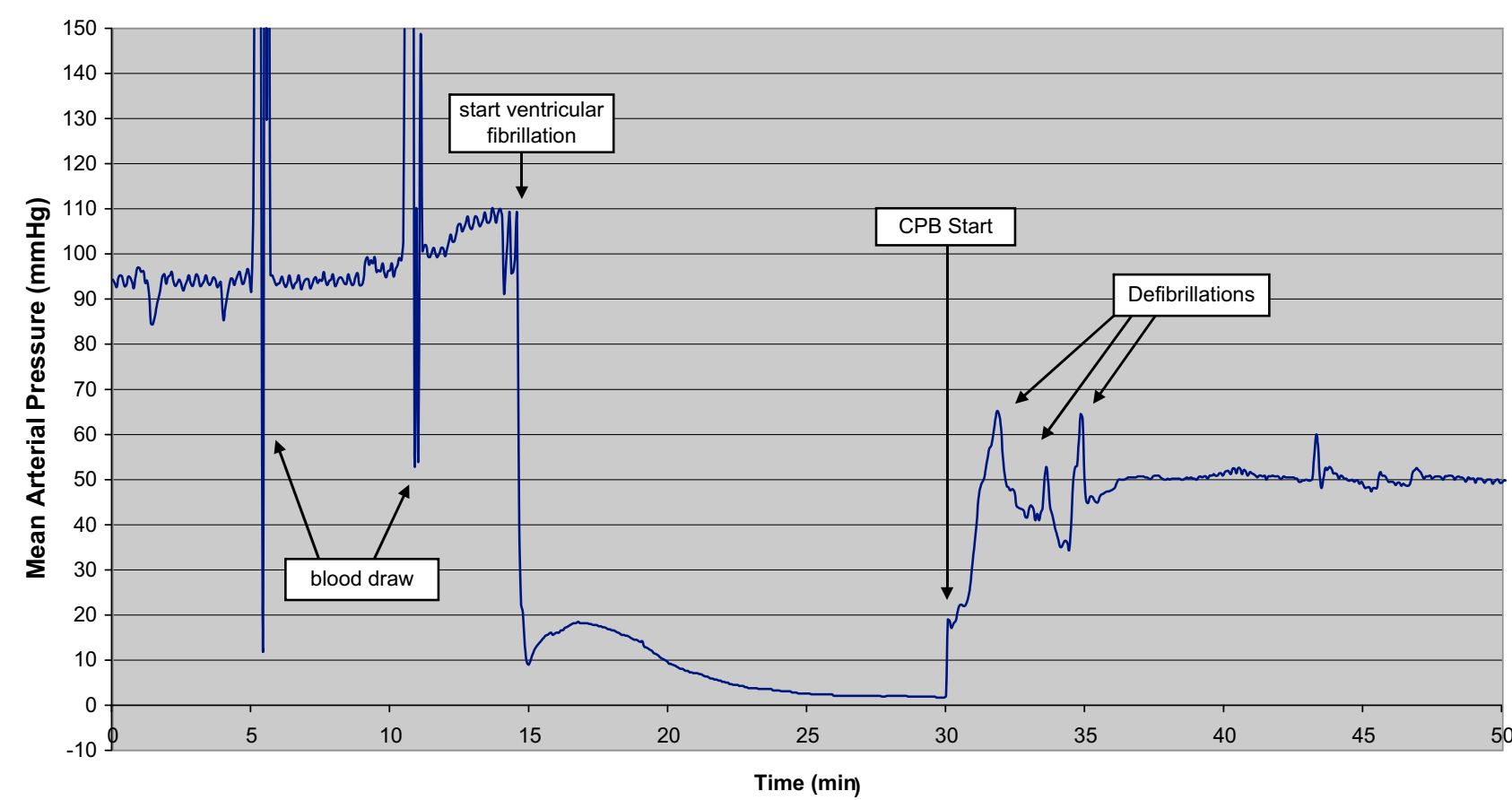

FIGURE E1. Mean arterial pressure before, during, and after 15 minutes of ventricular fibrillation (VF) in a single experiment. The figure shows an unmodified mean arterial pressure curve, including all artifacts caused by blood draw or defibrillations (arrows). Note the spontaneous increase in arterial pressure caused by peripheral vasoconstriction after ventricular fibrillation initiation followed by arterial pressure of less than $10 \mathrm{~mm} \mathrm{Hg}$ after 5 minutes of ventricular fibrillation. As part of the controlled reperfusion strategy, arterial pressure is kept low for the first 3 to 5 minutes on cardiopulmonary bypass $(C P B)$. The animal is taken off $\mathrm{CPB}$ after 60 minutes of controlled whole-body reperfusion. 
TABLE E1. Perioperative data after 15 minutes of cardiac arrest $(\mathbf{n}=7)$

\begin{tabular}{lr}
\hline Defibrillations to terminate VF (n) & $9 \pm 5$ \\
Time needed to stable SR (min) & $4.8 \pm 1.8$ \\
CPB (min) & $63.8 \pm 5.1$ \\
Extubation after CPB (min) & $140.0 \pm 8.7$ \\
Discharge to stable (h) & $2.6 \pm 0.3$ \\
\hline$V F$, Ventricular fibrillation; $S R$, sinus rhythm; $C P B$, cardiopulmonary bypass.
\end{tabular}

$V F$, Ventricular fibrillation; $S R$, sinus rhythm; $C P B$, cardiopulmonary bypass.
TABLE E3. Biochemical data: Control group $(n=4)$

\begin{tabular}{lcc}
\hline & Baseline & End of experiment \\
\hline AST (U/L) & $28 \pm 9$ & $37 \pm 18$ \\
ALT (U/L) & $59 \pm 7$ & $48 \pm 6$ \\
CK (U/L) & $4937 \pm 3547$ & $4243 \pm 2893$ \\
NSE $(\mu \mathrm{g} / \mathrm{L})$ & $0.5 \pm 0.1$ & $0.5 \pm 0.0$ \\
\hline
\end{tabular}

$A S T$, Aspartate aminotransferase; $A L T$, alanine aminotransferase; $C K$, creatinine kinase; NSE, neuron-specific enolase.
TABLE E2. Hemodynamic data before CPB, after CPB, and at the end of the operation $(n=7)$

\begin{tabular}{|c|c|c|c|}
\hline & Baseline & $\begin{array}{c}\text { End } \\
\text { of CPB }\end{array}$ & $\begin{array}{c}\text { End of } \\
\text { operation }\end{array}$ \\
\hline HR (beats/min) & $78 \pm 16$ & $96 \pm 34$ & $114 \pm 12$ \\
\hline MAP (mm Hg) & $80 \pm 7$ & $67 \pm 14$ & $61 \pm 10$ \\
\hline $\mathrm{AP}$, systolic $(\mathrm{mm} \mathrm{Hg})$ & $103 \pm 6$ & $89 \pm 23$ & $100 \pm 4$ \\
\hline $\mathrm{AP}$, diastolic $(\mathrm{mm} \mathrm{Hg})$ & $63 \pm 9$ & $53 \pm 6$ & $40 \pm 11$ \\
\hline MPAP (mm Hg) & $12 \pm 3$ & $25 \pm 2$ & $18 \pm 2$ \\
\hline PAP, systolic (mm Hg) & $19 \pm 2$ & $34 \pm 4$ & $30 \pm 2$ \\
\hline PAP diastolic (mm Hg) & $6 \pm 4$ & $17 \pm 6$ & $9 \pm 6$ \\
\hline $\mathrm{CVP}(\mathrm{mm} \mathrm{Hg})$ & $4 \pm 2$ & $6 \pm 3$ & $8 \pm 4$ \\
\hline PCWP $(\mathrm{mm} \mathrm{Hg})$ & $5 \pm 3$ & $4 \pm 2$ & $9 \pm 4$ \\
\hline $\mathrm{CI}\left(\mathrm{L} \cdot \min ^{-1} \cdot \mathrm{m}^{-2}\right)$ & $4.6 \pm 1.1$ & $5.1 \pm 0.6$ & $5.2 \pm 1.1$ \\
\hline SVI $\left(\mathrm{mL} \cdot\right.$ beat $\left.^{-1} \cdot \mathrm{m}^{-2}\right)$ & $61 \pm 13$ & $55 \pm 17$ & $46 \pm 11$ \\
\hline SVRI (dynes $\cdot \mathrm{s}^{-1} \cdot \mathrm{cm}^{-5} \cdot \mathrm{m}^{-2}$ ) & $1382 \pm 33$ & $1166 \pm 14$ & $827 \pm 33$ \\
\hline PVRI (dynes $\cdot \mathrm{s}^{-1} \cdot \mathrm{cm}^{-5} \cdot \mathrm{m}^{-2}$ ) & $120 \pm 4$ & $404 \pm 8$ & $140 \pm 5$ \\
\hline $\operatorname{LVSWI}\left(\mathrm{g} \cdot \mathrm{m}^{-1} \cdot \mathrm{m}^{-2}\right)$ & $66 \pm 16$ & $54 \pm 18$ & $38 \pm 10$ \\
\hline $\operatorname{RVSWI}\left(\mathrm{g} \cdot \mathrm{m}^{-1} \cdot \mathrm{m}^{-2}\right)$ & $9 \pm 3$ & $18 \pm 8$ & $11 \pm 3$ \\
\hline
\end{tabular}

$C P B$, Cardiopulmonary bypass; $H R$, heart rate; $M A P$, mean arterial pressure; $A P$, arterial pressure; $M P A P$, mean pulmonary arterial pressure; $P A P$, pulmonary arterial pressure; $C V P$, central venous pressure; $P C W P$, pulmonary capillary wedge pressure; $C I$, cardiac index; SVI, stroke volume index; SVRI, systemic vascular resistance index; $P V R I$, pulmonary vascular resistance index; $L V S W I$, left ventricular stroke work index; $R V S W I$, right ventricular stroke work index.
TABLE E4. Biochemical data: Treatment group $(n=4)$

\begin{tabular}{lccc}
\hline & Baseline & End of CPB & $\begin{array}{c}\text { End of experiment } \\
\text { (day 7) }\end{array}$ \\
\hline AST (U/L) & $34 \pm 8$ & $36 \pm 15$ & $49 \pm 33$ \\
ALT (U/L) & $37 \pm 17$ & $31 \pm 7$ & $93 \pm 77$ \\
CK (U/L) & $2172 \pm 859$ & $3225 \pm 2587$ & $2739 \pm 2272$ \\
NSE $(\mu \mathrm{g} / \mathrm{L})$ & $0.20 \pm 0.10$ & $0.20 \pm 0.08$ & $1.00 \pm 0.30$ \\
\hline
\end{tabular}

$\overline{A S T \text {, Aspartate aminotransferase; } A L T \text {, alanine aminotransferase; } C K \text {, creatinine }}$ kinase; $N S E$, neuron-specific enolase. 